\title{
Exogenous Salicylic and Ascorbic Acids Delay Peel Enzymatic Browning and Improve Quality of Dried Figs Under Low-Temperature Storage
}

\author{
Ahmed Irchad ${ }^{1,2, \dagger}$, Lahcen Hssaini ${ }^{1, *}+{ }^{\oplus}$, Rachid Razouk ${ }^{1}$ (D), Mohamed Chabbi ${ }^{2}$, Jamal Charafi ${ }^{1(D)}$, \\ Abderrahman Bouassab ${ }^{2}$ \\ 1 National Institute of Agricultural Research (INRA), Morocco \\ 2 Abdelmalek Essâadi University, Faculty of Sciences and Technics, Laboratory of Physical-Chemistry of Materials, Natural \\ Substances and Environment, Department of Chemistry, P.O. Box 416, 90010 Tangier, Morocco \\ * Correspondence: hssaiini@ gmail.com (L.H.); \\ $\dagger$ These authors have equally contributed to this work
}

Scopus Author ID 57209320167

Received: 22.10.2021; Revised: 23.11.2021; Accepted: 25.11.2021; Published: 11.12.2021

\begin{abstract}
Dried figs undergo undesirable changes during storage, particularly browning reactions. An approach to this issue is using, separately, antioxidants such as ascorbic acid and salicylic acid as antienzymatic browning agents. The aforementioned chemical agents were tested at the concentrations 0.1 , 0.2 , and $0.3 \%$ during 6 weeks-storage at $4{ }^{\circ} \mathrm{C}$, for dried figs sealed within polyethylene terephthalate bags. For both agents, the results demonstrated that a concentration of $0.3 \%$ lowered the browning index compared to the control by 55 and $54 \%$, respectively. Compared to other concentrations, the same concentration suppressed polyphenol oxidase to 75 and $80 \%$, respectively. A significant impact ( $p<$ 0.05 ), for both treatments, particularly at $0.3 \%$, was obtained on dried figs quality by lowering the total phenols loss and antioxidant capacity loss during the storage period. The results of vibrational spectroscopy were able to confirm the same pattern of the polyphenols compared to those examined by UV-Visible spectrophotometry, revealing thus a decreasing absorbance. A similar tendency was revealed using integrated intensity around the phenols vibration within the region of $1175-940 \mathrm{~cm}^{-1}$, as the concentrations of anti-browning agents increased. Thus, pre-storage ascorbic and salicylic acids treatments at $0.3 \%$ on dried figs could be appropriate to delay enzymatic browning and quality loss and, therefore to extend their shelf-life.
\end{abstract}

Keywords: enzymatic browning; polyphenol oxidase; vibrational spectroscopy; salicylic acid; ascorbic acid.

(c) 2021 by the authors. This article is an open-access article distributed under the terms and conditions of the Creative Commons Attribution (CC BY) license (https://creativecommons.org/licenses/by/4.0/).

\section{Introduction}

Growing demands for fruits and vegetables in forms where they can be consumed as easily accessible snacks has always been a major concern for the agri-food industry and continues to be a worthwhile yet challenging endeavor [1,2]. Figs (Ficus carica L.) and especially dried figs are emblematic food of the Mediterranean countries as the species is abundantly cultivated in such hot, dry climates [3]. There is little research in spoilage prevention methods and preserving their health-promoting properties, despite the importance of dried figs. Indeed, after harvest, at its fully ripe stage, figs generally contain more than $75 \%$ water [4], and given this characteristic of perishability, it is exposed to deterioration very quickly. Keeping them fresh has always been the best way to maintain their nutritional value 
for health through technological enhancement treatments $[5,6]$. However, such a decision is difficult to maintain throughout the distribution chain since it requires low temperatures and involves high costs [7,8]. For centuries, many alternatives have been practiced to overcome this, such as salting, dehydration, and fermentation [9]. Since drying prolongs its shelf life, dried fig is very popular and is important in the consumer market [10]. However, the fig undergoes several modifications and attacks during this process, such as biochemical reactions and microbial growth, leading to its senescence and deterioration [11]. Some of these changes persist after drying, such as unwanted browning reactions [12-14].

Under the term "browning" are grouped a set of phenomena that cause a reduction in quality, alteration of color, and organoleptic properties related to flavor, texture, and loss of nutrients. Consumers' appearance changes affect the sensory evaluation of dried figs, as browning is often linked to rotting $[15,16]$. Due to its polyphenols richness, the susceptibility of fig to enzymatic browning is high, and surface browning is the main cause of its deterioration during and after drying [14]. Over 50\% of the fruit industry's losses have been attributed to enzymatic browning, one of the biggest problems in fruit storage and processing [17]. This phenomenon, which represents enzymatic oxidation of polyphenols, is mainly attributed to the action of polyphenol oxidases (PPO), which catalyze the conversion of polyphenols into quinones, which constitute very unstable species that polymerize, leading to the formation of heavy molecular pigments, usually brown or black called "melanins" [15,16,18].

Sulfites are well-known anti-browning agents widely used for their effectiveness in food processing to prevent browning [19,20]. However, as the apparent safety of sulfite additives led to their widespread use, reports began to appear during the 1970s that consuming foods containing sulfites was associated with adverse health reactions [21]. Symptoms reported range from mild in some people to very severe in others, and in some people, these reactions can be life-threatening [16,22]. Faced with this situation, over the past decade, there has been a lot of research to replace sulfite treatment with less harmful anti-browning agents. Various healthier and safer anti-browning agents have recently gained considerable attention, including ascorbic and salicylic acids, which are able to inhibit the activity of PPO, either by lowering or increasing the $\mathrm{pH}$ or by inactivating the enzyme by chelating copper at its active site to inhibit the catalysis reaction [23-26]. Its low cost, low toxicity, and antioxidant and anti-free radical properties make ascorbic acid (vitamin C) the anti-browning agent that best meets the criteria for replacing sulfites in the food industry due to its preservative effects attributed to the reduction of reactive quinones to the original colorless diphenols [27,28]. Several investigations recommend its use at concentrations between 0.1 and $0.3 \%$ [29-31]. Likewise, salicylic acid (SA), which is a phenolic compound harmless to human health, has shown effective inhibition of enzymatic browning from several sources [32-34] due to a competitive inhibition mechanism of SA on the PPO activity [35]. Its role in inducing plant defense against various forms of biotic and abiotic stress has also been reported [35,36]. On freshly cut Chinese chestnut (Castanea mollissima), the effect of SA on enzymatic browning was studied by Zhou et al. [33] using concentrations between 0.1 and $0.5 \%$. With higher concentrations, the effect was significantly large. Similar results have been reported in several studies using the antibrowning agents mentioned above [17,35,37].

As far as we know, there is no data regarding Moroccan dried fig browning monitoring and preventing. To date, several studies worldwide have been carried out to find unharmful strategies to prevent food enzymatic browning. These strategies were mainly assayed using biochemical markers, such as PPO activity, polyphenols kinetic, and browning index. 
However, very few studies have investigated this phenomenon by combining these markers with vibrational spectroscopy as a highly sensitive and non-destructive method [38]. The present study investigated the effects of Ascorbic and salicylic acids on enzymatic browning and PPO activity in dried figs by combining biochemical assays using UV spectrophotometry with Fourier Transform Infrared spectroscopy (FTIR) using chemometrics.

\section{Materials and Methods}

\subsection{Plant material and growing conditions.}

350 fresh fruits samples of Ficus carica L. "El Qoti Lebied" cultivar, one of the most locally cultivated clones, was harvested during September 2020 at their full ripening stage from the ex-situ collection. This collection belong to the experimental station of the National Institute of Agricultural Research (INRA), in northern Morocco ( $x=511,600 ; y=370,250 ; z$ $=480 \mathrm{~m}$ ). This collection is 14-year-old trees planted in a completely random design and spacings of $5 \times 3 \mathrm{~m}$. The trees are driven in a cup, and drip-irrigated daily, from March to October, with an average daily dose of 55 liters/tree. The orchard is planted on loamy clay soil, quite rich in organic matter (2.07\%) and usually fertilized with 170,90 , and $120 \mathrm{~kg} \mathrm{ha}^{-1}$ of $\mathrm{N}$, $\mathrm{P}_{2} \mathrm{O}_{5}$, and $\mathrm{K}_{2} \mathrm{O}$, respectively. Figs were considered fully ripe when the receptacle was threequarters reddish-purple and when they were easily separated from the twig. Selected fruits had uniform size and maturity, with no diseases and visual blemishes. Initial moisture content was determined using the oven-dried method as described by AOAC. [39] and was noted to be 78 $\pm 1 \%$ wet basis (w.b.).

\subsection{Fruit pretreatment and drying.}

Figs were distributed according to an experimental design depending on the treatment with the anti-browning agents. The selection of the soak temperature, duration, and concentrations was based on the available literature. Thus, as described by Ali et al. [30] and Zhou et al. [33], fruits were immersed for $5 \mathrm{~min}$ in distilled water (control) or in the following concentrations of $0.1,0.2$, and $0.3 \%$, either ascorbic acid or acid salicylic respectively. Subsequently, the fruits were dried in a hot air dryer at a temperature of $80{ }^{\circ} \mathrm{C}$, and a speed of $300 \mathrm{~m}^{3} / \mathrm{h}$. Drying was stopped at a moisture content of $25 \%$ according to the Commercial Grade Standards for Dried Figs developed by the United Nations Economic Commission for Europe [40]. All the dried samples (315 dried figs) with the same moisture content were packaged and sealed in polyethylene terephthalate (PET) bags (size: 17 x $12 \mathrm{~cm} \mathrm{L/W}$; permeability: 50-100 and $245.83-408.64 \mathrm{~cm}^{3} \cdot \mu \mathrm{m} / \mathrm{m}^{2} . \mathrm{h}$. atm for $\mathrm{O}_{2}$ and $\mathrm{CO}_{2}$, respectively; permeability to water vapor: $16.25-21.25$ g. $\mu \mathrm{m} / \mathrm{m}^{2} . \mathrm{h}$ ) to serve as replicates. For each treatment, twenty-one bags, each containing fifteen fruits, were prepared. Samples were arranged in a complete randomized design with one fruit per repeat for each treatment and stored at $4{ }^{\circ} \mathrm{C}$ for six weeks. At the end of the experimental storage period, samples' water activity (aw) was $0.41,0.4$, and 0.38 for the dried samples treated with salicylic and ascorbic acids and the control, respectively. This was measured using a calibrated electric hygrometer (HygroLab, Rotronic, Bassersdorf, Switzerland). All measurements were performed in triplicate. 


\subsection{Browning index determination.}

Color variation of the dried figs according to the different treatments (control included), during the periodic monitoring, along the experimental storage was measured using a Minolta CM-700 colorimeter (Minolta Camera Co., Osaka, Japan), standardized with white and black calibration. All measurements were obtained from four random points located on opposite sides of the equatorial region of the fruit. The average of the four measurements was taken as a single replica, with less than $0.5 \%$ error. Fifteen replications per sample were considered. The color was studied with reference to the CIE L*, $\mathrm{a}^{*}, \mathrm{~b}^{*}$ color coordinates with the D65 illuminant, the SCI mode, and an observation angle of $10^{\circ}$. Low reflectance glass (Minolta CRA51/1829-752) was placed between the samples and the equipment. The determined CIE L*, $a^{*}, b^{*}$ coordinates referred to clarity $\left(\mathrm{L}^{*}\right)$, redness ( $\mathrm{a}^{*}$, red/green coordinate), and yellowing ( $\mathrm{b}^{*}$, yellow-blue coordinate). Browning Index (BI), which represents the purity of the brown color, and which is reported as an important parameter in the processes where enzymatic browning occurs [41,42], was calculated using equations 1 and 2 below described according to Palou et al. [43].

$$
\begin{gathered}
\mathrm{BI}=[100(\mathrm{x}-0.31)] / 0.172(\text { Eq. } 1) \\
\text { where: } \mathrm{x}=(\mathrm{a} *+1.75 \mathrm{~L}) /(5.645 \mathrm{~L}+\mathrm{a} *-3.012 \mathrm{~b} *)(\mathrm{Eq} .2)
\end{gathered}
$$

\subsection{Polyphenoloxydase (PPO) activity determination.}

Extraction and determination of the PPO enzymatic activity were carried out as described by Zhou et al. [33]. Briefly, $20 \mathrm{~g}$ of dried fig were homogenized in $100 \mathrm{~mL}$ of citrate phosphate buffer (0.05 M, pH 5.6) using an IKA T-18 Basic Ultra-Turrax homogenizer (IKA Werke GmbH \& Co ., Staufen, Germany). The mixture was centrifuged for $30 \mathrm{~min}$ at $0{ }^{\circ} \mathrm{C}$ and $10,000 \mathrm{~g}$, and the supernatant was then added with $100 \mathrm{~mL}$ of the same buffer. Enzymatic activity of PPO was evaluated by adding $0.1 \mathrm{M}$ catechol $(1 \mathrm{~mL})$ as a substrate to a mixture of $0.1 \mathrm{M}$ phosphate citrate buffer $(\mathrm{pH} 5.6,3 \mathrm{~mL})$ to the enzymatic extract solution $(0.5 \mathrm{~mL})$. The change in absorbance at $420 \mathrm{~nm}$ was measured every $30 \mathrm{~s}$ for $3 \mathrm{~min}$ using a UV-1700 spectrophotometer Shimadzu, Japan. Results were represented by a specific activity, defined as an increase in absorbance per minute in $1 \mathrm{mg}$ enzyme of the reaction mixture $(\Delta \mathrm{A} 420 / \mathrm{min} / \mathrm{mg})$.

\subsection{Determination of total phenolic content (TPC).}

After drying, and every 15 days, on each treatment with its different concentrations, a sample was taken at random and was subjected to extraction for phenolic compounds. Extraction was performed with reference to the method developed by Sanders et al. [44], and slightly modified by Xie and Bolling. [45]. Total polyphenols content (TPC) of the dried fig extracts was determined with reference to the micro Folin-Ciocalteu method described by Waterhouse. [46]. Briefly, $1 \mathrm{~g}$ aliquots of each sample powder were homogenized in $20 \mathrm{ml}$ of ethanol and ultra-pure water (80:20, v/v) at $4{ }^{\circ} \mathrm{C}$ for 15 min using an IKA T-18 Basic UltraTurrax homogenizer (IKA Werke GmbH \& Co., Staufen, Germany). After centrifugation for $10 \mathrm{~min}$ at $4{ }^{\circ} \mathrm{C}$ at $3000 \mathrm{~g}$, the supernatant was removed from the residue, and the extraction was repeated three times. Supernatants were combined and filtered through Whatman No.1 filter paper. Afterward, $40 \mu \mathrm{L}$ of extract were added to $3160 \mu \mathrm{L}$ of ultrapure water, $200 \mu \mathrm{L}$ of the Folin-Ciocalteu reagent, and $600 \mu \mathrm{L}$ of $20 \%$ sodium carbonate solution. After $30 \mathrm{~min}$ of incubation at $40{ }^{\circ} \mathrm{C}$, the absorbance was measured at $765 \mathrm{~nm}$ (UV-1700 Shimadzu, Japan). The 
TPC is expressed as gallic acid equivalent per dry weight of fig fruit (mg GAE/gdw). The analysis was performed in triplicate, and the results were expressed as $\mathrm{mg}$ of gallic acid equivalent (GAE) per $100 \mathrm{~g}$.

\subsection{Antioxidant activity.}

Antioxidant activity was assessed by the free radical scavenging methodology, using DPPH (radical 2,2-diphenyl-1-picrylhydrazyl) and ABTS (2,2-azinobis-(3ethylbenzothiazoline- 6-sulphonic acid) tests. DPPH assay was performed according to the method adapted from Kumar et al. [47] with slight modifications. Briefly, to $0.2 \mathrm{~mL}$ of the ethanolic extract was added $3.8 \mathrm{~mL}$ of the freshly prepared DPPH solution (by dissolving in $96 \%$ ethanol $\left.\left(0.026 \mathrm{mg} \cdot \mathrm{mL}^{-1}\right)\right)$. After $30 \mathrm{~min}$ of incubation, the absorbance was read at $515 \mathrm{~nm}$, and the antioxidant capacity was calculated according to the equation below. ABTS test was performed according to Re et al. [48] by reacting an aqueous solution of $7 \mathrm{mM}$ ABTS (3.6 g.L${ }^{1}$ ) with $2.45 \mathrm{mM}$ potassium persulfate $\left(0.662 \mathrm{~g} . \mathrm{L}^{-1}\right)$, followed by incubation of the mixture in the dark for $12-16 \mathrm{~h}$ at room temperature. ABTS solution was then diluted with ethanol to obtain a table absorbance of $0.7 \pm 0.02$ at $734 \mathrm{~nm}$. Hence, $20 \mu \mathrm{l}$ of the extract or the distilled water (control) were mixed with $1 \mathrm{ml}$ of the diluted ABTS solution. After $6 \mathrm{~min}$ at $30^{\circ} \mathrm{C}$, the absorbance was measured at $734 \mathrm{~nm}$. After $6 \mathrm{~min}$ at $30^{\circ} \mathrm{C}$, the absorbance was measured at $734 \mathrm{~nm}$. All essays were performed in triplicate, and antioxidant capacity values for both DPPH and ABTS were calculated using the equation (Eq. 3) below.

$$
\mathrm{I}(\%)=[(\text { Abs Control }- \text { Abs Sample }) / \text { Abs Control }] \times 100 \text { (Eq. 3) }
$$

\subsection{FTIR-ATR spectroscopy.}

Fourier transform infrared spectroscopy (FTIR) measurements were performed using the Bruker Vertex 70 FTIR spectrometer equipped with an ATR (Attenuated Total Reflection) accessory (Bruker Optics Inc., Ettlingen, Germany), in the region of 4000 to $450 \mathrm{~cm}^{-1}$ with a spectral resolution of $4 \mathrm{~cm}^{-1}$. Three scans were averaged for each FTIR spectrum on the infrared (IR) spectrum corresponding to the accumulation of 128 scans. Measurements were carried out by applying $50 \mu \mathrm{L}$ of the ethanolic extracts of each sample to the germanium crystal by spreading it using the pipette tip. Prior to evaluating the sample, a background spectrum was collected, which corresponds to an IR spectrum of an empty germanium crystal surface. This is automatically subtracted from the sample spectra. Crystal cell was cleaned between spectral collections using an ethanol rinse and hot water, then thoroughly dried with a soft tissue.

\subsection{Processing of FTIR-ATR infrared spectra.}

In order to correct multiplicative interference, a basic correction procedure was first performed on each IR spectrum [49]. ATR correction procedure was applied to the raw FTIR spectra. The processing parameters were summarized as follows: incidence angle $=45^{\circ}$; ATR reflection number $=1$; average refractive index of the sample $=1.5$; maximum interaction $=$ $50 ; 1.8 \mathrm{~mm}$ crystal surface. Peaks in each spectrum that indicate regions of vibration corresponding to sample biochemical fingerprints and areas were obtained using Essential FTIR software (version 3.50.183). In order to show the differences in absorbance between samples, the vibration corrected spectra of the phenol region were obtained using OriginPro v8.5 software (OriginLab Corporation Inc.). 


\subsection{Statistical data processing and chemometrics.}

Before statistical analysis, the data were tested for normality and homogeneity of variance to ensure the validity of the analysis. This was carried out using SPSS v22 software to test the significant differences between the samples. Experimental design consisted of a three-factor model which are treatments (AA and SA) $x$ applied concentration $(0,0.1,0.2$ and $0.3 \%)$ x storage period (0-6 weeks).

\section{Results and Discussion}

\subsection{Treatments effect on the browning index (BI).}

The instant enzymatic browning is the main factor that restricts the selling of dried figs. Therefore, BI is considered as an important index of the browning process and surface decay, and which increased from 10 to 60 after the six-week storage of control samples, while that of the AA and SA treated samples showed a low browning rate, which varied depending on the treatment and following the applied concentrations (Figure 1). Generally, treated figs maintained a low browning index during storage time. It is noteworthy that BI remained almost unchanged during the first week of storage. After that, treatment doses significantly impacted dried fig browning rate, which was negatively correlated to the treatment dose. Thus, overall, the samples treated with a concentration of $0.3 \%$ showed low BI compared to 0.1 and $0.2 \%$, particularly for SA. At the end of the storage time, the BI of samples treated with $0.3 \%$ of AA and SA was 34.25 and 33.64, representing 55 and 54\% of the control, respectively (Figure 1). The results showed that AA and SA delayed the browning reaction on the surface of dried fig during the cold storage time, and the effects were influenced by their respective concentrations. Both treatments showed the same effects, with no remarkable differences between them. Similar results were shown by Zhou et al. [33], who reported that SA had lowered BI of freshcut Chinese chestnut during six days storage. Zhang et al. [50] have also observed that melatonin treatment inhibited the postharvest browning of litchi fruit. The same results were found by Ali et al. [30], using cysteine, ascorbic acid, and citric acid as PPO inhibitors and anti-browning agents on lettuce-head fresh-cut.
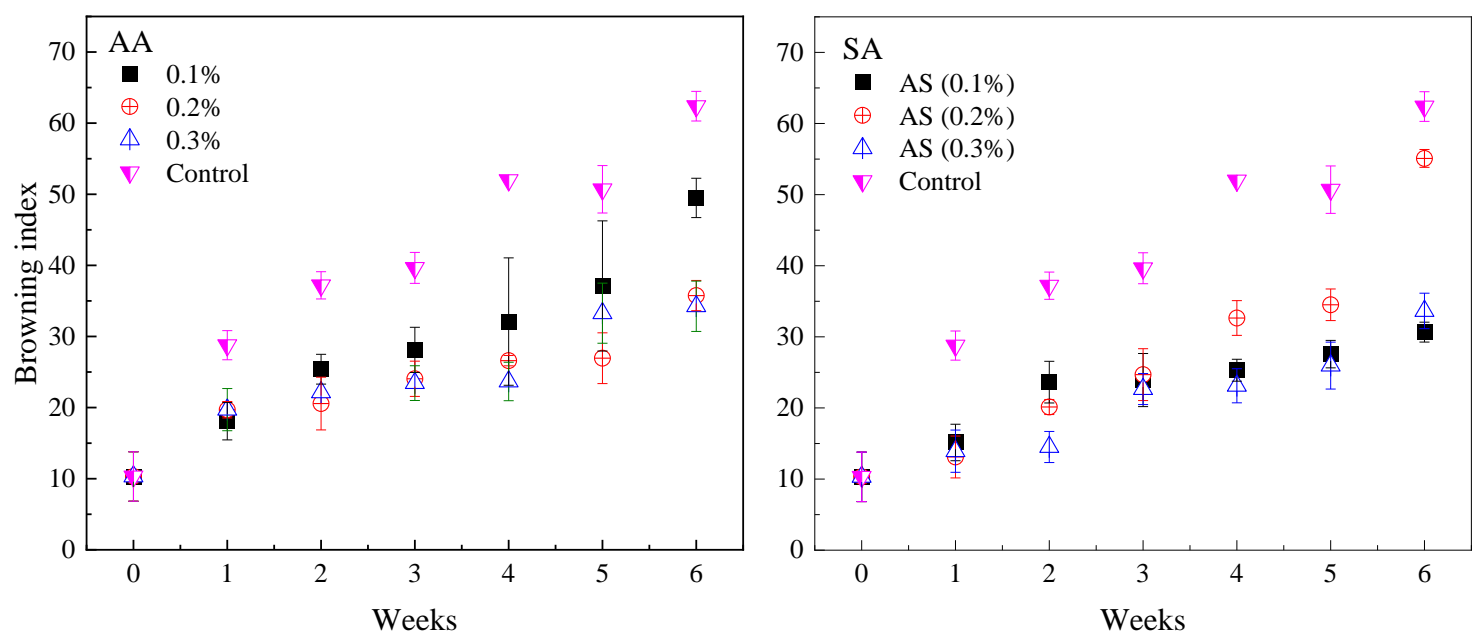

Figure 1. Browning index (BI) variation over six weeks storage as affected by different concentrations of ascorbic (AA) and salicylic acid (SA). Values are given as means \pm standard deviations ( $\mathrm{n}=3$ fruits). 
The authors stressed that high concentrations of ascorbic acid (>1.5\%) reduced the quinone instantly formed to the catechol (original substrate), whereas it showed a competitive mechanism at lower concentrations. The browning index has been proven to be the best indirect way to investigate the enzymatic activity in foods. It provides valuable information of color deterioration, representing the purity of brown color, indicating where the enzymatic browning process takes to convert polyphenols to quinones [35]. In this sense, the correlation between PPO and BI was given in Figure 2, showing all related statistics, including a high R-square value of 0.81 .
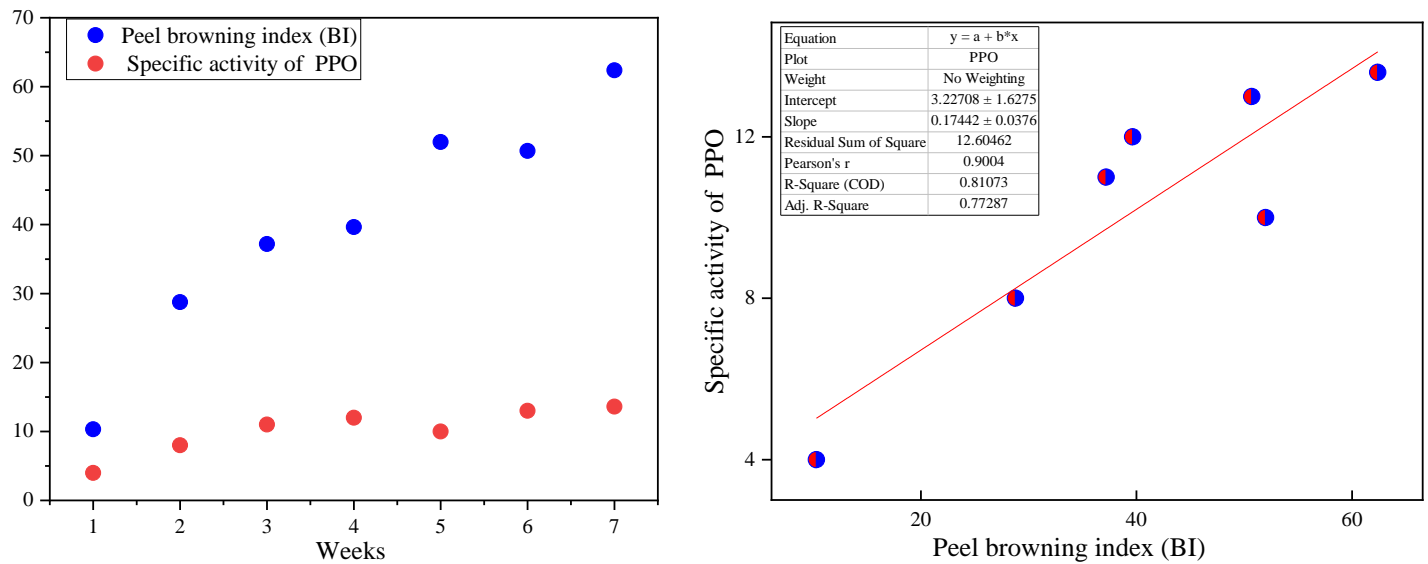

Figure 2. Correlation between the specific activity of polyphenol oxidase (PPO) and browning index (BI) in dried figs (example of control samples).

\subsection{Impact of processing on PPO activity.}

The changes in samples' PPO activity over time are shown in Figure 3. After six weeks storage period, AA and SA treatments had significantly reduced the specific activity of PPO compared to the control $(p<0.05)$. The specific PPO activity of untreated samples has increased by $200 \%$ after three-week storage, which is more than three times the initial value. However, it showed a low increase rate starting from the end of the third week. Treated samples displayed an increasing PPO activity during the first-week storage before it decreased substantially for the rest of the storage period. Thus, figs specific activity of PPO decreased to 17 and $25 \%$ of that of the first week as treated by 0.1 and $0.2 \%$ of AA, and therefore the PPO activity was lowered 15 to 13 times that of the control samples, respectively. A higher decrease rate of the PPO specific activity $(75 \%)$ was obtained AA treatment at $0.3 \%$ (Figure 3). After treatment with low SA concentration, the specific activity of PPO at week six was reduced to $7.5 \%$ compared to that of week one. This is equivalent to a specific PPO activity 15 times lower than the control samples. At 0.2 and $0.3 \%$ of AS treatment, a sharp decrease in specific PPO activity was observed, where it was decreased to 17 and $12 \%$, respectively at the end of each treatment, which corresponds to a lowering of 20 to 27 times compared to that of the control samples respectively (Figure 3). During the experimental storage period, the enzymatic activities of PPO of figs treated with AA and SA were significantly lower than those of control fruits. General inhibition of PPO activities by the anti-browning agents applied would consist of reduced contact between the enzymes and the substrates. In this sense, several authors have reported the PPO activity inhibition in the fruits by the treatments used in this trial, inhibiting effect and not by inactivation of the enzyme [51-53]. While the level of PPO activity lowering by ascorbic acid was $75 \%$ compared to the control, salicylic acid showed an $80 \%$ decrease in PPO activity, even if the two treatments showed similar kinetics during the storage period. The small increase in the PPO specific activity after the first week of storage, for all treatments, and 
all concentrations may be due to a synergistic effect of AS with certain polyphenols present in the crude enzyme, which may affect the binding of AA and SA in the active site of PPO, and subsequently the conversion of polyphenols to quinones [50]. Zhou et al. [33] report that the hydrogen bonds formed between the oxygen atoms of the anti-browning agent and the hydrogen atoms of the phenols may be the main factor leading to the inactivation of PPO. The inhibitory effect of AA and SA on the PPO activity had gradually become effective, with the increase in the concentration of the treatments. Investigations carried out on other browning inhibitors, such as cysteine and citric acid [35], chlorine dioxide [37], sodium chloride [54], and chitosan [55], have reported this phenomenon. In addition, various studies have shown that AA and AS are competitive inhibitors of PPO, which inhibits the conversion of polyphenols to quinones. Therefore the spontaneous polymerization of quinones to melanin leads to browning $[17,33,35,37,56]$.
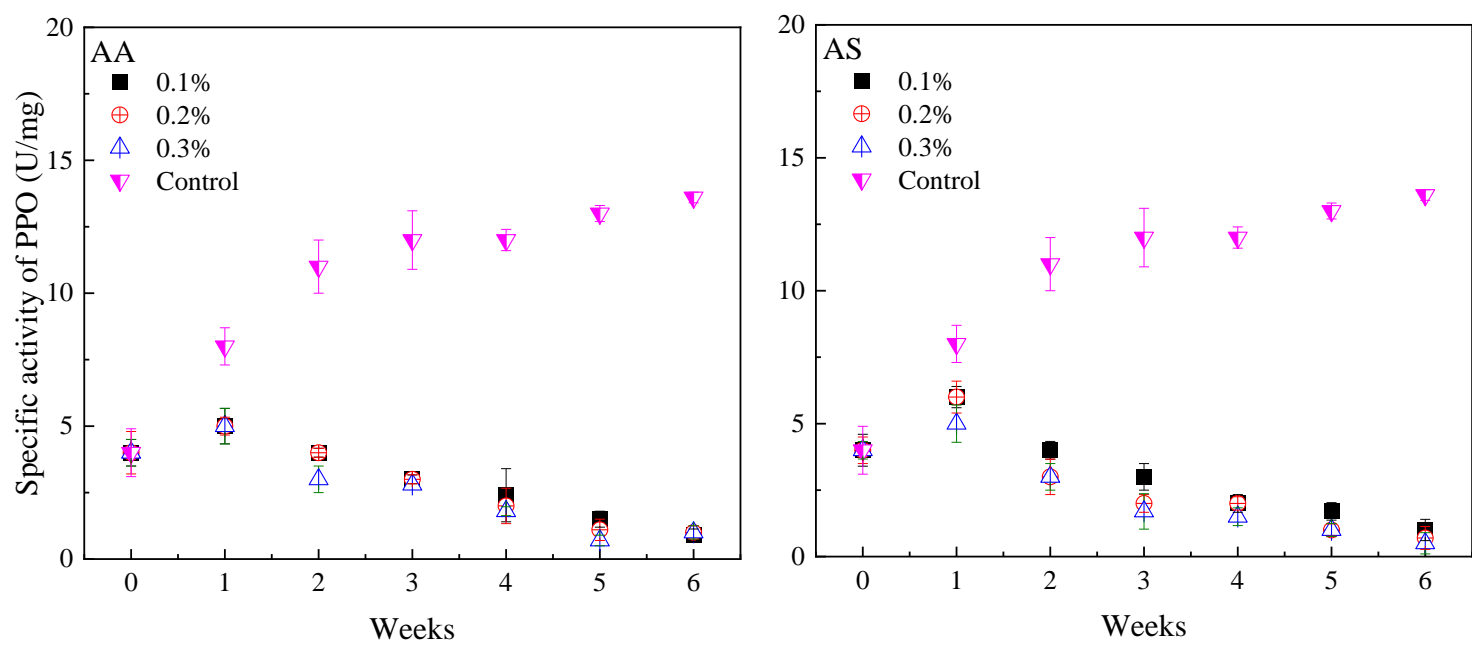

Figure 3. Variation of enzymatic specific activities of polyphenol oxidase (PPO) in dried figs over time (six weeks) (AA: ascorbic acid; SA: salicylic acid). Values are given as means \pm standard deviations $(\mathrm{n}=3$ fruits).

\subsection{Effects of treatments on total phenolic content (TPC) kinetic.}

Polyphenols are one of the main compounds implicated in fruit enzymatic browning. Total polyphenols contents (TPC) were measured, and their evolution was followed during the test along the storage period. Evaluation of total polyphenols kinetics revealed for both treated and control dried figs a significant decrease in levels as storage time increased (Figure 4). TPC increased during the first week of storage and then decreased significantly until the end of the storage period. With a sharp decrease during the first three weeks, control samples exhibited a very low TPC during the experiment, before remaining relatively constant at a low level for the two consecutive weeks. Finally, the curve showed a rate of relatively small decrease. After six weeks, TPC decreased to $17 \%$ at the start of the storage period in the control samples. Processed samples displayed a similar pace to their specific PPO activity, which resulted in a substantial increase in TPC during the first week of storage before decreasing until the sixth week of storage significantly. In samples treated with AA, this peak was remarkable, where the TPC was generally about $139.5 \mathrm{mg}$ GAE/100 g, compared to those treated with SA (120 mg GAE/100 g). According to Saito and Kawabata. [57], this finding can probably be explained by the suppression of the formation, and the dissipation of free radicals by the two antibrowning agents used, which results from the synergistic effect between the anti-browning agents with the compounds phenolics in the samples. Since AA and SA interfere with the FolinCiocalteu reagent, this phenomenon could also be attributed to the excessive amount of AA 
and SA with the soaking treatment. This has been demonstrated by Saito and Kawabata. [57]. Compared with AA, TPC levels were higher in the case of SA, which may also be explained by the action of the agents on the PPO catalytic reaction. Indeed, at $0.3 \%$, while AA reduced initial PPO activity by $75 \%$, SA suppressed up to $80 \%$. On the other hand, a relatively rapid decrease in TPC was observed with low concentrations of treatments.

Thus, TPC decreased to 30 and $33 \%$ of the initial value after six weeks of storage at $0.1 \%$ of the AA and SA treatments, while it was reduced to 13 and $16 \%$ after treatment with $0.3 \%$, respectively. Using the same concentration $(0.3 \%)$, it should be noted that throughout the storage period, TPC was maintained at higher levels in the samples treated with SA compared to AA. These results can be explained by the inhibition of phenolic compounds oxidation by the anti-browning agents used during storage time. In agreement with several previous investigations $[17,35,37,56]$, these results suggest that AA and SA treatments had beneficial effects on maintaining dried figs' total phenol content. During postharvest storage, reducing the oxidation of phenolic compounds ultimately helps reduce enzymatic browning [35]. Thus, the binding of anti-browning agents AA and SA into the PPO active site was probably associated with the higher level of TPC in the samples treated with these agents, subsequently preventing the conversion of polyphenols to quinones. This result suggests that AA and SA treatments inhibit the oxidation of phenolic compounds and consequently the browning process of dried figs.
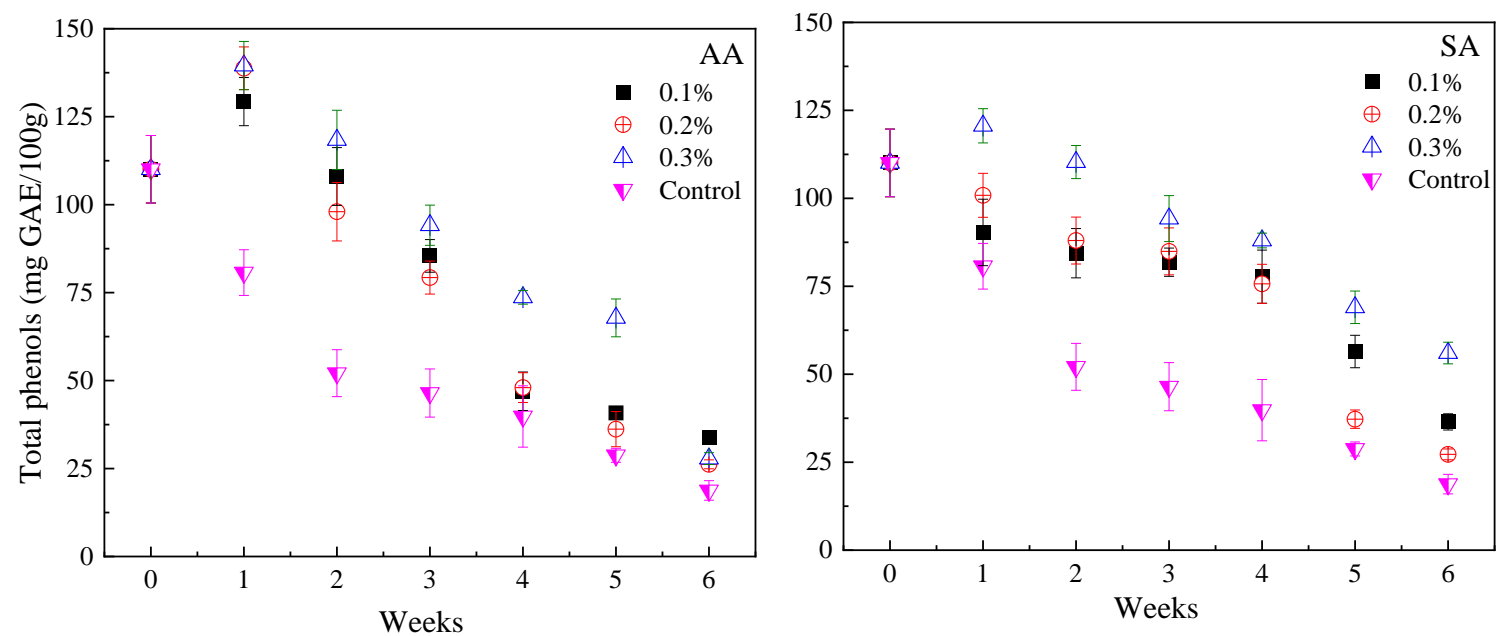

Figure 4. Total phenolic content (TPC) variations during storage as affected by different concentrations of ascorbic (AA) and salicylic acid (SA). Vertical bars show the standard error of the means, and data are the mean of three replicates.

\subsection{Effect on antioxidant activity by scavenging free radicals DPPH and ABTS.}

During storage, in order to evaluate the kinetics of dried figs' antioxidant capacity, tests for antioxidant activity by scavenging free radicals DPPH and ABST were applied to the samples under the different processing conditions. In both DPPH and ABTS trials, a significant decrease pattern similar to TPC in control and treated dried figs was observed throughout storage, with a typical increase during the first week (Figure 5). Compared to control figs, the decrease in antioxidant activity was significantly less in dried figs treated with AA and SA. In dried figs treated with AA and SA, DPPH scavenging activity decreased significantly from week 2 to 6 ( $p<0.05)$, which was in agreement with the previous study by Adiletta et al. [55] on fresh figs treated with ascorbic acid (1.5\%) and chitosan (1\%) for 9 days. Zhang et al. [58] reported the same results in litchi fruit as influenced by apple polyphenols. The authors pointed 
out that as storage time increased, there was a similar suppression of DPPH radical scavenging activity. The same was observed in the ABTS radical scavenging activity kinetics (Figure 5). After the first week to the end of the storage period, the ABTS radical scavenging activity in the dried figs treated with AA and SA decreased considerably $(p<0.05)$. Results showed a consistent trend with total phenolic content, suggesting that the antioxidant capacity kinetics of dried figs decrease due to accelerated senescence during storage [59]. These results suggest that AA and SA delay dried figs' antioxidant capacity decrease, and thus both treatments could maintain higher antioxidant activity compared to control samples, and this is probably related to the same effect they had on the kinetics of TPC during the storage period. AA and SA treatments mechanism to reduce browning in dried figs is probably related to their ability to delay the decrease in antioxidant activity, which has been observed through the kinetics of DPPH and ABTS radical scavenging, thus inhibiting the process for converting phenolic compounds into quinones. These are findings consistent with several investigations $[35,56,59]$.
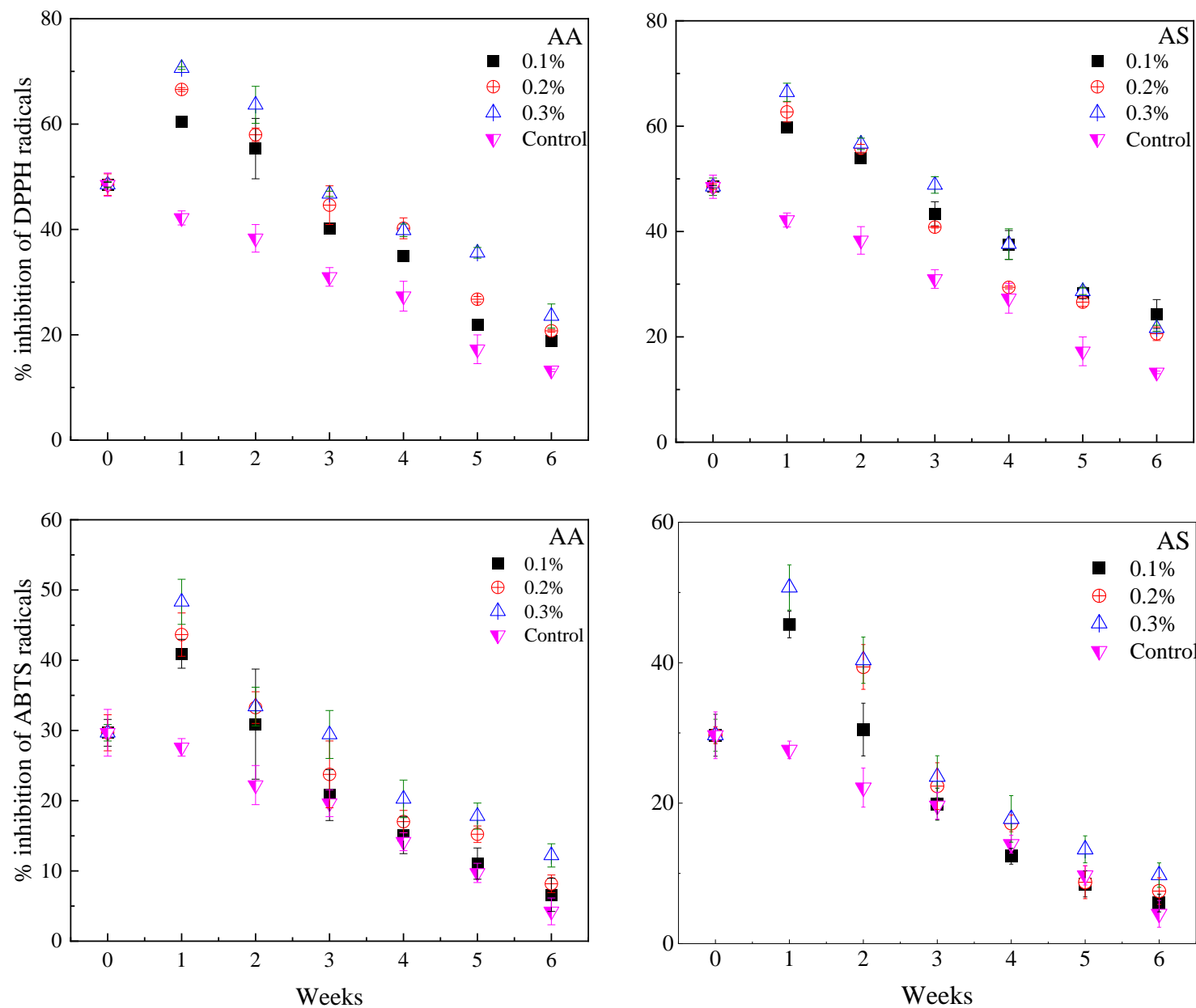

Figure 5. Changes in free radical scavenging activity (DPPH and ABTS) of dried figs treated by different concentrations $(0.1,0.2$, and $0.3 \%$ ) of ascorbic (AA) and salicylic acid (SA). Vertical bars show the standard error of the means, and data are the mean of three replicates.

\subsection{FTIR-ATR spectral analysis.}

Dried figs extracts analysis at the respective treatments by FTIR-ATR spectroscopy revealed spectral bands shown in Figure 6. Between 4000 and $450 \mathrm{~cm}^{-1}$, in relation to spectra shape and depending on the peaks, we can note five vibration zones (3700-3000, 3000-2800, $1800-1500,1500-1175,1175-940 \mathrm{~cm}^{-1}$ ) associated with wavelengths characteristic of a given chemical group. It should be noted that the spectrum is made up of spectral bands specific to 
each treatment under all the concentrations, along the storage period, which is superimposed, where the five zones of vibrations are found, and obviously with a similarity. The first region is assigned to $\mathrm{OH}$ stretching vibrations resulting from hydrogen bonding in cellulose. According to Schwanninger et al. [60] and Oh et al. [61], the main vibration of this region which is visible at $3336 \mathrm{~cm}^{-1}$, can be associated with the intramolecular hydrogen bond between $\mathrm{C}(3) \mathrm{OH} \cdots \mathrm{O}(5)$ and $\mathrm{C}(6) \mathrm{O} \cdots \mathrm{O}(2) \mathrm{H}$. It was also possible for us to detect in our samples, as shown in the present figure, a peak in the absorption band between $3000 \mathrm{~cm}^{-1}$ and $2800 \mathrm{~cm}^{-1}$. This implies the presence of $\mathrm{C}-\mathrm{H}, \mathrm{O}-\mathrm{H}$, and $\mathrm{NH}_{3}$ groups, which can be assigned to carbohydrate compounds, phenolics, carboxylic acids, as well as free amino acids [62,63]. Between 1800 $\mathrm{cm}^{-1}$ and $1600 \mathrm{~cm}^{-1}$, the spectrum has a small shoulder in the FTIR spectra, which has been attributed to deformation $\mathrm{OH}$ in the plane, to elongation $\mathrm{C}=\mathrm{O}$ of carboxylic ester type and stretching $\mathrm{C}=\mathrm{O}$ of proteins [64-66]. Between 1500 and $1175 \mathrm{~cm}^{-1}$, the absorbance bands would correspond to the phosphodiester groups and are probably the result of several weak peaks that could not be differentiated in the analyzed samples.
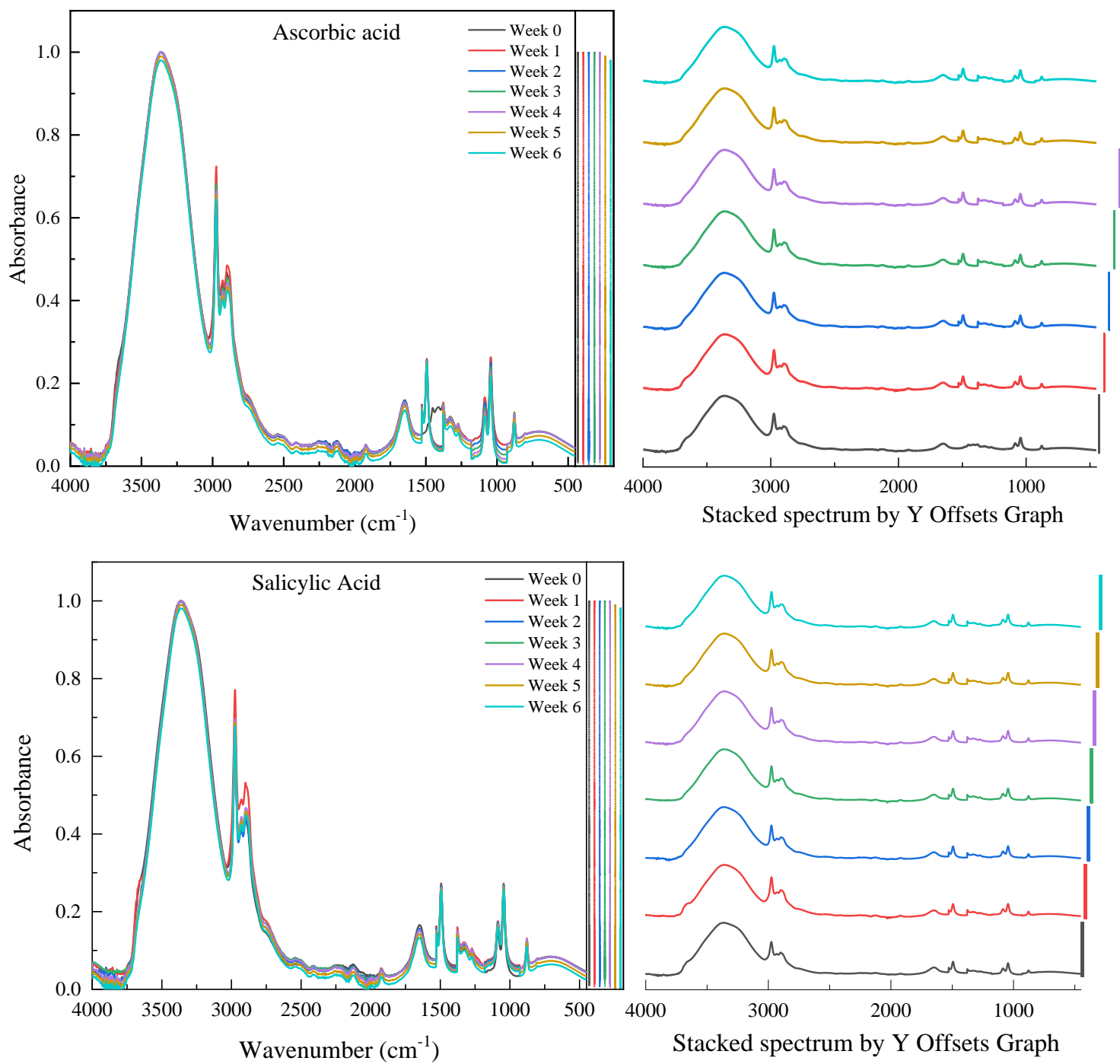

Figure 6. Typical ATR-FTIR spectra of dried fig samples (example of $0.1 \%$ treatment) measured in the region of $450-4000 \mathrm{~cm}^{-1}$.

Various investigations connect these bands with vibration around $1458.15 \mathrm{~cm}^{-1}$, which could probably be associated with the curvature of $\mathrm{CH}_{2}$ and the methylene deformation of protein $[67,68]$, the vibration to $1392 \mathrm{~cm}^{-1}$ which is most likely assigned to carbohydrates or 
the lateral chain of amino acids [69,70], the vibration at $1315 \mathrm{~cm}^{-1}$, which is associated to tilting $\mathrm{CH}_{2}$ [60], and vibration at about $1155 \mathrm{~cm}^{-1}$, which is the result of $\mathrm{CO}$ stretching [70]. Finally, the vibrations in the region of $1175-940 \mathrm{~cm}^{-1}$ are made up of a small peak at $1086 \mathrm{~cm}^{-1}$, probably assigned to the $\mathrm{C}-\mathrm{OH}$ group and a pointed peak around $1044 \mathrm{~cm}^{-1}$ attributed to $\mathrm{CC}$ and $\mathrm{CO}$ stretching in the glucide structure and $\mathrm{CO}$ in phenol [71].

Ascorbic acid
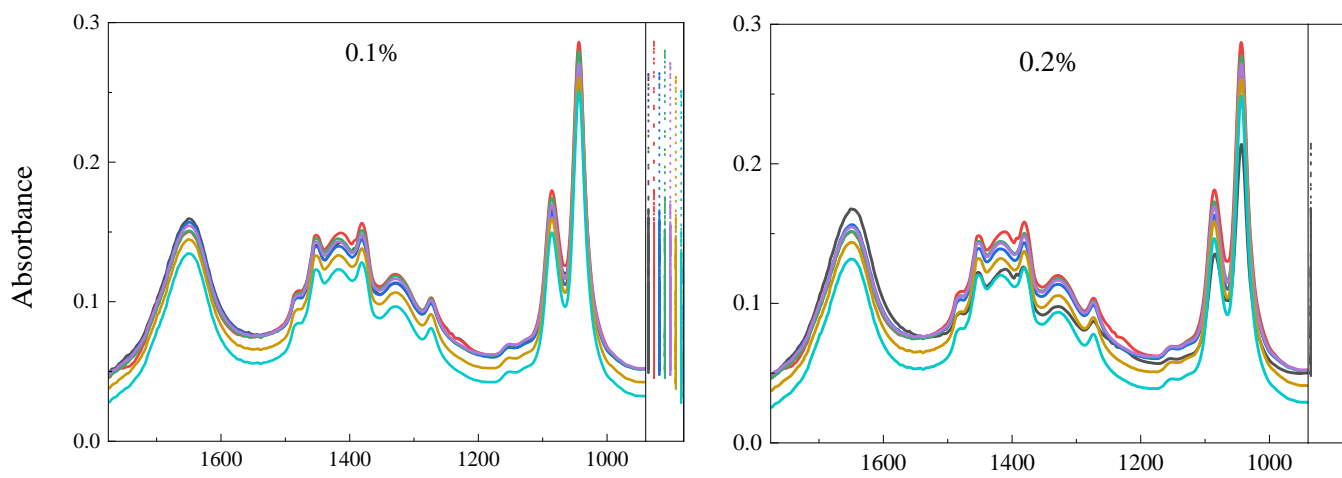

Weeks
-0
-1
-2
-3
-5
-6
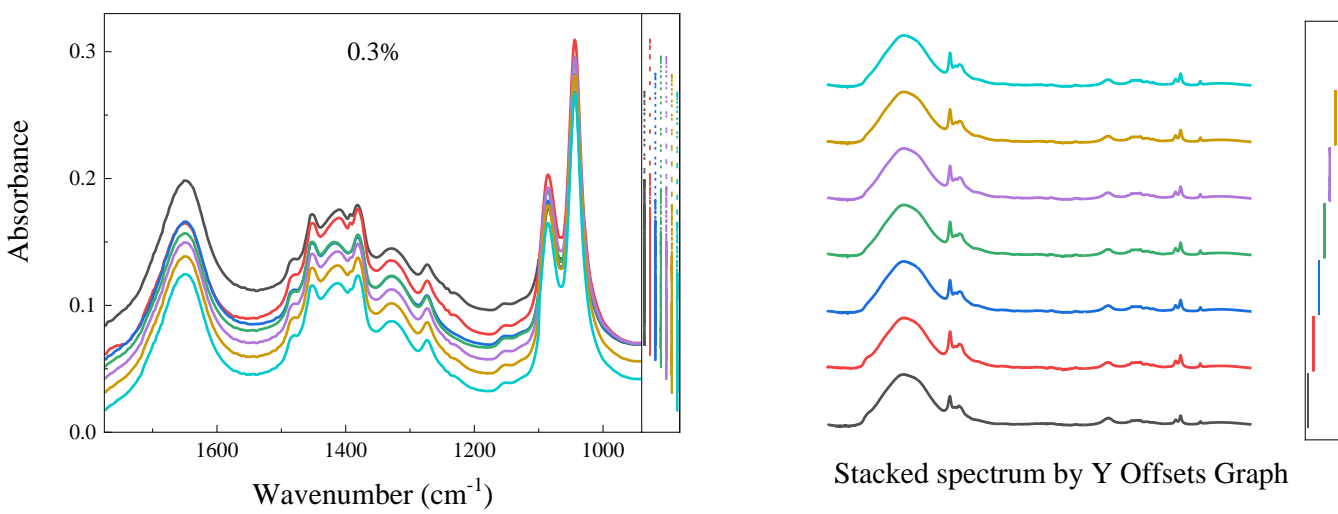

Salicylic acid
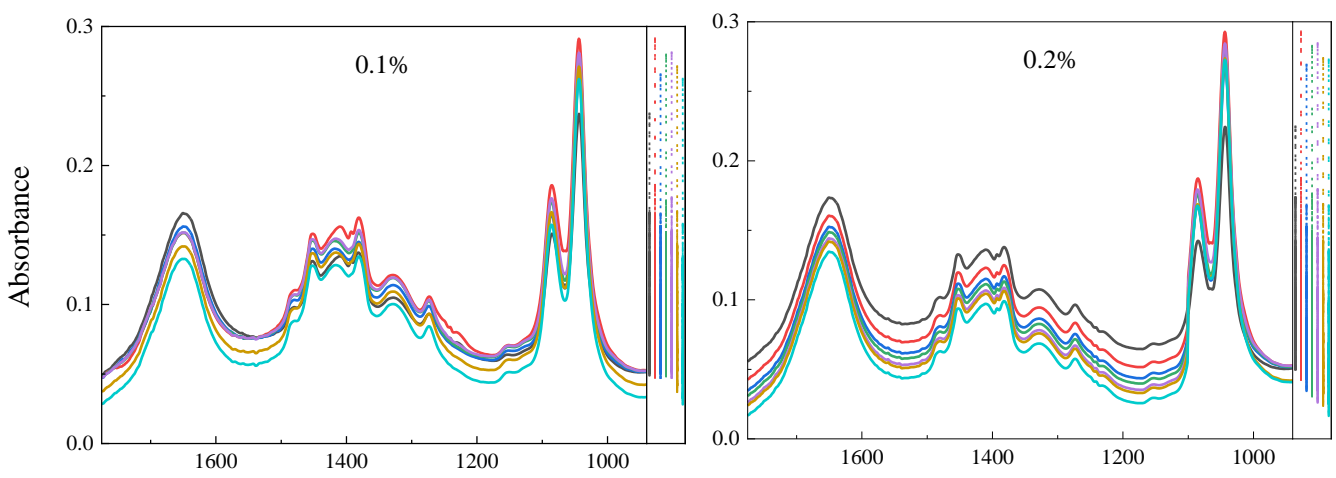

Weeks
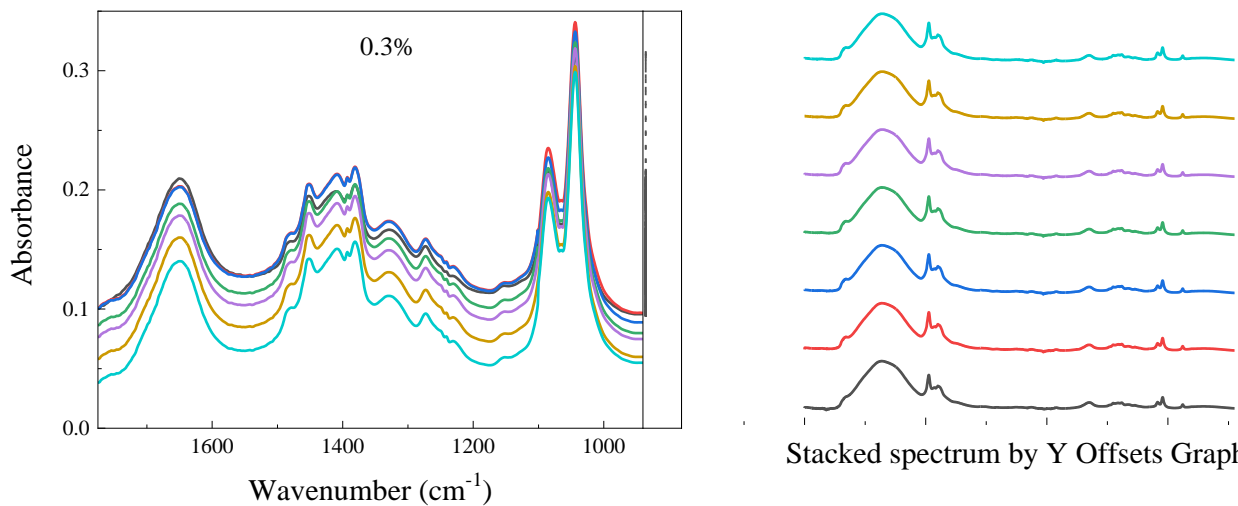

Stacked spectrum by Y Offsets Graph

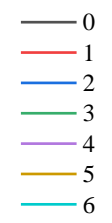

Figure 7. ATR-FTIR spectra in the region of $1775-940 \mathrm{~cm}^{-1}$ as a function of storage period and treatment dose. Each sample IR represents the mean of 3 spectra. 
The effect of anti-browning agents used is particularly observed in this region because it is often linked to phenols, the subjects of spontaneous conversion to quinones, and enzymatic browning.

Since it is difficult to visualize the impact of each treatment on the absorbances of the samples, and based on overall results obtained with the FTIR-ATR spectroscopy, and of our major interest for the phenolic compounds because of their determining implication in enzymatic browning, it was particularly interesting to draw the infrared spectra (IR) of each treatment in the absorption band between $1775 \mathrm{~cm}^{-1}$ and $940 \mathrm{~cm}^{-1}$ which comprise the phenols (Figure 7). As the storage time increases, the absorbance decreases gradually, according to the results above. Also, as the concentration of each treatment increases, the overlapping of IR bands becomes less remarkable in both treatments. This characteristic is observed in the samples processed by SA.

Using the Essential FTIR software, the integrated intensity of the $1175-940 \mathrm{~cm}^{-1}$ region, which includes phenols' vibration, has been calculated and plotted for each treatment (Figure 8). With the storage time advancement, the integrated intensities have shown a downward trend in all samples, indicating the decrease of phenolic compounds in the samples. This trend reversed with the increase in each treatment concentration. Thus, as the concentration of antibrowning agents increased, integrated intensities increased. Even by being a qualitative method, FTIR spectroscopy has been useful for characterizing changes in dried samples and the effect of AA and SA treatment and their corresponding concentrations. In previous studies, FTIR-ATR fingerprints showed an excellent ability to discriminate from the distribution of numerous biomolecules, with a significant flow resolution to distinguish several food samples including fruits, vegetables, or drinks, for example, biosynthesis of silver nanoparticles in figs [72], polysaccharides of the cell wall of the olive pulp [73], the authentication of the pomegranate juice concentrate [74] and the discrimination of bovine gelatin, swine and fish [38]. In this approach, the level of resolution on the classification suggests the usefulness of FTIR-ATR spectroscopy in screening as accurate, fast, with minimal sample preparation and inexpensive technology in addition to being respectful of the environment compared to classic chemical methods. Baltacioğlu et al. [75] investigated with the FTIR technique. It gave satisfactory results in the study of structural changes and PPO activity during heat treatment in the temperature range of 25 to $80^{\circ} \mathrm{C}$.
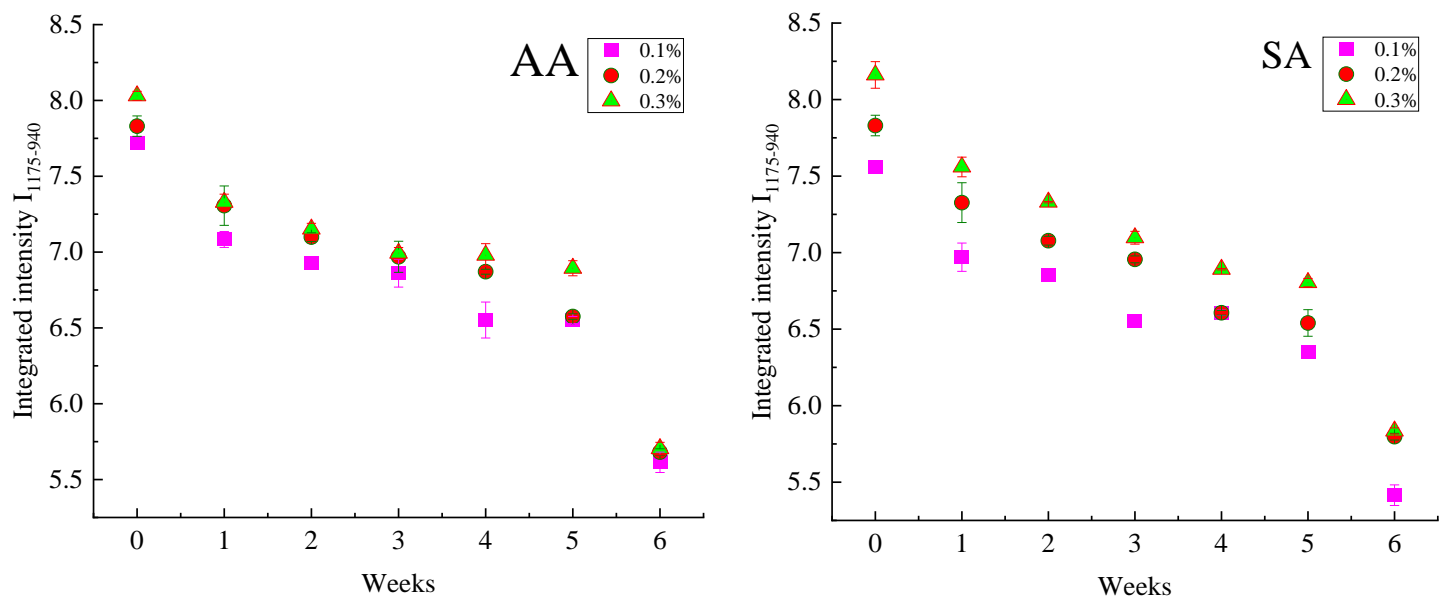

Figure 8. Integrated intensity of the $1175-940 \mathrm{~cm}^{-1}$ vibration (phenols vibration) as a function of storage period and treatment dose showing that the decrease of the intensity was lowered by the decrease of treatment dose.

(AA: ascorbic acid; SA: salicylic acid). 
In our study, FTIR results were generally consistent with those of TPC kinetics, antioxidant activity, BI, and PPO, which showed a significant impact of AA and SA treatments on the decrease in BI and PPO activity, in addition to maintaining the TPC and antioxidant capacity at a higher level compared to control samples. The characteristics thus unveiled in this approach have important implications on the basis that they may encourage the potential use of FTIR-ATR fingerprints in a pattern of chemotypes distribution discrimination.

\section{Conclusions}

Enzymatic browning is a challenging endeavor for dried fig marketability leading to a considerable quality loss. Through this report, it can be concluded that ascorbic and salicylic acids treatment at the concentration of $0.3 \%$ was the most effective for controlling the fig peel enzymatic browning at low-temperature storage. The same concentration delayed the quality loss through lowering polyphenols and antioxidant activity decrease. The vibrational spectroscopy technique using ATR-FTIR was consistent with previous ones since the absorbance showed a decreasing rate in the region of phenols vibration $\left(1175-940 \mathrm{~cm}^{-1}\right)$, which was lowered as the anti-browning agents' concentration decreased. Integrated intensities observed at this vibration region also showed a low decrease in high inhibitor concentrations. Considering these results, this study suggests the use of SA, which showed a slight superiority in its effect to lower enzymatic browning in dried figs. Both applied treatments are harmless to human health, easy to use, and did not significantly differ in their prices. The present study provides interesting and promising results on the use of ascorbic and salicylic acids as an unharmful anti-browning agent for inhibition of dried fig enzymatic browning and, at the same time lowering their antioxidant quality loss.

\section{Funding}

This research did not receive any specific grant from funding agencies in the public, commercial, or not-for-profit sectors.

\section{Acknowledgments}

The authors thank Zahra Oussi Ali and Ali Hussaini for their support in this study.

\section{Conflicts of Interest}

The authors declare no conflict of interest.

\section{References}

1. Mostafidi, M.; Sanjabi, M.R.; Shirkhan, F.; Zahedi, M.T. A review of recent trends in the development of the microbial safety of fruits and vegetables. Trends Food Sci. Technol. 2020, 103, 321-332, https://doi.org/10.1016/j.tifs.2020.07.009.

2. Balali, G.I.; Yar, D.; Dela, V.G.A.; Adjei-Kusi, P. Microbial Contamination, an Increasing Threat to the Consumption of Fresh Fruits and Vegetables in Today's World. Int. J. Microbiol. 2020, 2020, 1-13, https://doi.org/10.1155/2020/3029295.

3. Zare, H.; Jalili, H. Comparison of Dried 'Sabz' fig (Ficus carica cv. Sabz) Harvesting, Drying, Disinfection, and Storage Methods. Int. J. Fruit Sci. 2020, 20, S1741-S1750, https://doi.org/10.1080/15538362.2020.1830918. 
4. Hssaini, L.; Charafi, J.; Razouk, R.; Hernández, F.; Fauconnier, M.; Ennahli, S.; Hanine, H. Assessment of Morphological Traits and Fruit Metabolites in Eleven Fig Varieties (Ficus Carica L.). Int. J. Fruit Sci. 2020, 20, 8-28, , https://doi.org/10.1080/15538362.2019.1701615.

5. Saif, S.; Hanif, M.A.; Rehman, R.; Hanif, M.; Khan, O.; Khan, S. Chapter 21 - Figs. In Medicinal Plants of South Asia; Hanif, M.A., Nawaz, H., Khan, M.M., Byrne, H.J., Eds.; Elsevier, 2020; pp. 273-286 ISBN 9780-08-102659-5, https://doi.org/10.1007/s10695-021-00952-7.

6. Active Edible Coating to Preserve Fresh Figs. Chem. Eng. Trans 87, 181-186, https://doi.org/10.3303/CET2187031.

7. Martínez-Damián, M.T.; Cruz-Arvizu, O.; Cruz-Alvarez, O. Effect of modified atmosphere packaging on nutraceutical quality and overall appearance of figs stored at $1{ }^{\circ} \mathrm{C}$. Not. Bot. Horti Agrobot. Cluj-Napoca 2020, 48, 2292-2305, https://doi.org/10.15835/nbha48412076.

8. Levaj, B.; Repajić, M.; Lončarić, S.; Dragović-Uzelac, V.; Pelaić, Z.; Pedisić, S. Fig freezing in sugar solutions. Glasnik zaštite bilja 2021, 44, 42-51, https://doi.org/10.31727/gzb.44.3.6.

9. Desa, M.; Nurlaila, W.; Mohammad, M.; Fudholi, A. Review of drying technology of fig. Trends Food Sci. Technol. 2019, 88, 93-103, , https://doi.org/10.1016/j.tifs.2019.03.018.

10. Oksar, R.; Şen, F.; Aksoy, U. The effects of pretreatments on color, composition and storability of dried 'Sarılop' fig fruit. Acta Hortic. 2017, 347-352, https://doi.org/10.4315/0362-028X.JFP-18-193.

11. Sadeghi, R.; Seyedabadi, E.; Moghaddam, R.M. Microwave Application for Controlling Oryzaephilus surinamensis Insects Infesting Dried Figs and Evaluation of Product Color Changes Using an Image Processing Technique. J. Food Prot. 2019, 82, 184-188, doi:10.4315/0362-028x.jfp-18-193.

12. Moon, K.M.; Kwon, E.-B.; Lee, B.; Kim, C.Y. Recent Trends in Controlling the Enzymatic Browning of Fruit and Vegetable Products. Mol. 2020, 25, 2754, https://doi.org/10.3390/molecules25122754.

13. Al-Amrani, M.; Al-Alawi, A.; Al-Marhobi, I. Assessment of Enzymatic Browning and Evaluation of Antibrowning Methods on Dates. Int. J. Food Sci. 2020, 2020, 8380461-9, https://doi.org/10.1155/2020/8380461.

14. González, M.N.; Massa, G.A.; Andersson, M.; Turesson, H.; Olsson, N.; Fält, A.-S.; Storani, L.; Oneto, C.A.D.; Hofvander, P.; Feingold, S.E. Reduced Enzymatic Browning in Potato Tubers by Specific Editing of a Polyphenol Oxidase Gene via Ribonucleoprotein Complexes Delivery of the CRISPR/Cas9 System. Front. Plant Sci. 2020, 10, 1649, https://doi.org/10.3389/fpls.2019.01649.

15. Whitaker, J.R.; Lee, C.Y. Recent Advances in Chemistry of Enzymatic Browning. In Proceedings of the ACS Symposium Series; American Chemical Society (ACS), 1995; Vol. 600, pp. 2-7.

16. McEvily, A.J.; Iyengar, R.; Otwell, W.S. Inhibition of enzymatic browning in foods and beverages. Crit. Rev. Food Sci. Nutr. 1992, 32, 253-273, https://doi.org/10.1080/10408399209527599.

17. Gao, H.; Chai, H.; Cheng, N.; Cao, W. Effects of 24-epibrassinolide on enzymatic browning and antioxidant activity of fresh-cut lotus root slices. Food Chem. 2017, 217, 45-51, https://doi.org/10.1016/j.foodchem.2016.08.063.

18. Février, H.; Le Quéré, J.-M.; Le Bail, G.; Guyot, S. Polyphenol profile, PPO activity and pH variation in relation to colour changes in a series of red-fleshed apple juices. LWT 2017, 85, 353-362, https://doi.org/10.1016/j.lwt.2016.11.006.

19. D’Amore, T.; Di Taranto, A.; Berardi, G.; Vita, V.; Marchesani, G.; Chiaravalle, A.E.; Iammarino, M. Sulfites in meat: Occurrence, activity, toxicity, regulation, and detection. A comprehensive review. Compr. Rev. Food Sci. Food Saf. 2020, 19, 2701-2720, https://doi.org/10.1111/1541-4337.12607.

20. Arora, S.; Goraya, R.K.; Siddiqui, S.; Gehlot, R. Influence of anti-browning treatments on enzymatic browning, distinctive properties, and microbiological characteristics of banana pulp during short-term frozen storage. J. Food Process. Preserv. 2021, 45, 15259, https://doi.org/10.1111/jfpp.15259.

21. Stohs, S.J.; Miller, M.J. A case study involving allergic reactions to sulfur-containing compounds including, sulfite, taurine, acesulfame potassium and sulfonamides. Food Chem. Toxicol. 2014, 63, 240-243, https://doi.org/10.1016/j.fct.2013.11.008.

22. Koksal, N.; Yildirim, Z.; Gokirmak, M.; Hasanoglu, H.; Mehmet, N.; Avc1, H. The role of nitric oxide and cytokines in asthma-like syndrome induced by sulfur dioxide exposure in agricultural environment. Clin. Chim. Acta 2003, 336, 115-122, https://doi.org/10.1016/S0009-8981(03)00334-6.

23. Soliva, R.C.; Elez, P.; Sebastián, M.; MartínO. Evaluation of browning effect on avocado purée preserved by combined methods. Innov. Food Sci. Emerg. Technol. 2000, 1, 261-268, https://doi.org/10.1016/S14668564(00)00033-3. 
24. Soliva-Fortuny, R.; Elez-MartínezP.; Sebastián-Calderó, M.; Martin-Belloso, O. Kinetics of polyphenol oxidase activity inhibition and browning of avocado purée preserved by combined methods. J. Food Eng. 2002, 55, 131-137, https://doi.org/10.1016/S0260-8774(02)00027-4.

25. Yang, C.-P.; Fujita, S.; Ashrafuzzaman, M.; Nakamura, N.; Hayashi, N. Purification and Characterization of Polyphenol Oxidase from Banana (Musa sapientumL.) Pulp. J. Agric. Food Chem. 2000, 48, 2732-2735, https://doi.org/10.1021/jf991037+.

26. Zhou, L.; Liu, W.; Xiong, Z.; Zou, L.; Chen, J.; Liu, J.; Zhong, J. Different modes of inhibition for organic acids on polyphenoloxidase. Food Chem. 2016, 199, 439-446, https://doi.org/10.1016/j.foodchem.2015.12.034.

27. Nicolas, J.J.; Richard-Forget, F.C.; Goupy, P.M.; Amiot, M.J.; Aubert, S.Y. Enzymatic browning reactions in apple and apple products. Crit. Rev. Food Sci. Nutr. 1994, 34, 109-157, https://doi.org/10.1080/10408399409527653.

28. Martinez, M.; Whitaker, J.R. The biochemistry and control of enzymatic browning. Trends Food Sci. Technol. 1995, 6, 195-200, https://doi.org/10.1016/S0924-2244(00)89054-8.

29. Wang, S.; Lin, T.; Man, G.; Li, H.; Zhao, L.; Wu, J.; Liao, X. Effects of Anti-browning Combinations of Ascorbic Acid, Citric Acid, Nitrogen and Carbon Dioxide on the Quality of Banana Smoothies. Food Bioprocess Technol. 2013, 7, 161-173, https://doi.org/10.1007/s11947-013-1107-7.

30. Ali, H.M.; El-Gizawy, A.M.; El-Bassiouny, R.E.I.; Saleh, M.A. Browning inhibition mechanisms by cysteine, ascorbic acid and citric acid, and identifying PPO-catechol-cysteine reaction products. J. Food Sci. Technol. 2014, 52, 1-9, https://doi.org/10.1007/s13197-011-0249-8.

31. Sikora, M.; Świeca, M. Effect of ascorbic acid postharvest treatment on enzymatic browning, phenolics and antioxidant capacity of stored mung bean sprouts. Food Chem. 2018, 239, 1160-1166, https://doi.org/10.1016/j.foodchem.2017.07.067.

32. Zhang, J.-P.; Chen, Q.-X.; Song, K.-K.; Xie, J.-J. Inhibitory effects of salicylic acid family compounds on the diphenolase activity of mushroom tyrosinase. Food Chem. 2006, 95, 579-584, https://doi.org/10.1016/j.foodchem.2005.01.042.

33. Zhou, D.; Li, L.; Wu, Y.; Fan, J.; Ouyang, J. Salicylic acid inhibits enzymatic browning of fresh-cut Chinese chestnut (Castanea mollissima) by competitively inhibiting polyphenol oxidase. Food Chem. 2015, 171, 1925, https://doi.org/10.1016/j.foodchem.2014.08.115.

34. Liao, T.; Liu, J.; Sun, Y.; Zou, L.; Zhou, L.; Liu, C.; Terefe, N.S.; Liu, W. Differential inhibitory effects of organic acids on pear polyphenol oxidase in model systems and pear puree. LWT 2019, 118, 108704, https://doi.org/10.1016/j.lwt.2019.108704.

35. Tareen, M.J.; Abbasi, N.A.; Hafiz, I.A. Postharvest application of salicylic acid enhanced antioxidant enzyme activity and maintained quality of peach cv. 'Flordaking' fruit during storage. Sci. Hortic. 2012, 142, 221228, https://doi.org/10.1016/j.scienta.2012.04.027.

36. War, A.R.; Paulraj, M.G.; War, M.Y.; Ignacimuthu, S. Role of salicylic acid in induction of plant defense system in chickpea (Cicer arietinumL.). Plant Signal. Behav. 2011, 6, 1787-1792, https://doi.org/10.4161/psb.6.11.17685.

37. Remorini, D.; Landi, M.; Tardelli, F.; Lugani, A.; Massai, R.; Graziani, G.; Fogliano, V.; Guidi, L. Effect of Chlorine Dioxide and Ascorbic Acid on Enzymatic Browning and Shelf Life of Fresh-Cut Red Delicious and Granny Smith Apples. J. Food Process. Preserv. 2015, 39, 2925-2934, https://doi.org/10.1111/jfpp.12544.

38. Cebi, N.; Durak, M.Z.; Toker, O.S.; Sagdic, O.; Arici, M. An evaluation of Fourier transforms infrared spectroscopy method for the classification and discrimination of bovine, porcine and fish gelatins. Food Chem. 2016, 190, 1109-1115, https://doi.org/10.1016/j.cub.2017.05.064.

39. Baur, F.J.; Ensminger, L.G. The Association of Official Analytical Chemists (AOAC). J. Am. Oil Chem. Soc. 1977, 54, 171-172, https://doi.org/10.1007/BF02670789.

40. Bey, M.B.; Richard, G.; Meziant, L.; Fauconnier, M.; Louaileche, H. Effects of sun-drying on physicochemical characteristics, phenolic composition andin vitroantioxidant activity of dark fig varieties. $J$. Food Process. Preserv. 2016, 41, e13164, https://doi.org/10.1111/jfpp.13164.

41. Guerrero, S.; Alzamora, S.; Gerschenson, L. Optimization of a combined factors technology for preserving banana purée to minimize colour changes using the response surface methodology. J. Food Eng. 1996, 28, 307-322, https://doi.org/10.1016/0260-8774(95)00036-4.

42. Castañón, X.; Argaiz, A.; López-Malo, A. Effect of storage temperature on the microbial and color stability of banana purée with addition of vanillin or potassium sorbate / Efecto de la temperatura de almacenamiento 
en la estabilidad microbiológica y en el color del puré de plátano con la adición de vainillina o sorbato de potasio. Food Sci. Technol. Int. 1999, 5, 51-58, https://doi.org/10.1177/108201329900500105.

43. Palou, E.; Lopez-Malo, A.; Barbosa-Canovas, G.V.; Welti-Chanes, J.; Swanson, B.G. Polyphenoloxidase Activity and Color of Blanched and High Hydrostatic Pressure Treated Banana Puree. J. Food Sci. 1999, 64, 42-45, https://doi.org/10.1111/j.1365-2621.1999.tb09857.x.

44. Sanders, T.H.; McMichael, R.W.; Hendrix, K.W. Occurrence of Resveratrol in Edible Peanuts. J. Agric. Food Chem. 2000, 48, 1243-1246, https://doi.org/10.1021/jf990737b.

45. Xie, L.; Bolling, B. Characterisation of stilbenes in California almonds (Prunus dulcis) by UHPLC-MS. Food Chem. 2014, 148, 300-306, https://doi.org/10.1016/j.foodchem.2013.10.057.

46. Waterhouse, A.L. Determination of Total Phenolics. Curr. Protoc. Food Anal. Chem. 2002, 6, I1.1.1-I1.1.8, https://doi.org/10.1002/0471142913.faa0101s00.

47. Kumar, B.; Smita, K.; Cumbal, L.; Debut, A. Ficus carica (Fig) Fruit Mediated Green Synthesis of Silver Nanoparticles and its Antioxidant Activity: a Comparison of Thermal and Ultrasonication Approach. BioNanoScience 2016, 6, 15-21, https://doi.org/10.1007/s12666-017-1061-6.

48. Re, R.; Pellegrini, N.; Proteggente, A.; Pannala, A.; Yang, M.; Rice-Evans, C. Antioxidant activity applying an improved ABTS radical cation decolorization assay. Free Radic. Biol. Med. 1999, 26, 1231-1237 https://doi.org/10.1016/S0891-5849(98)00315-3.

49. Shen, X.; Xu, L.; Ye, S.; Hu, R.; Jin, L.; Xu, H.; Liu, W. Automatic baseline correction method for the openpath Fourier transform infrared spectra by using simple iterative averaging. Opt. Express 2018, 26, A609A614, https://doi.org/10.1364/OE.26.00A609.

50. Zhang, H.; Liu, X.; Chen, T.; Ji, Y.; Shi, K.; Wang, L.; Zheng, X.; Kong, J. Melatonin in Apples and Juice: Inhibition of Browning and Microorganism Growth in Apple Juice. Mol. 2018, 23, 521, https://doi.org/10.3390/molecules23030521.

51. Arias, E.; González, J.; Oria, R.; Buesa, J.G. Ascorbic Acid and 4-Hexylresorcinol Effects on Pear PPO and PPO Catalyzed Browning Reaction. J. Food Sci. 2007, 72, C422-C429, https://doi.org/10.1111/j.17503841.2007.00484.x.

52. Kausar, A.; Babar, M.E.; Khan, S.; Ahmad, M.S. Controlling of Polyphenol Oxidase-Based Browning in Selected Fruits and Vegetables. Agrobiol. Rec. 2020, 2, 69-75, https://doi.org/10.47278/journal.abr/2020.016.

53. Bhat, T.A.; Rather, A.H.; Hussain, S.Z.; Naseer, B.; Qadri, T.; Nazir, N. Efficacy of ascorbic acid, citric acid, ethylenediaminetetraacetic acid, and 4-hexylresorcinol as inhibitors of enzymatic browning in osmodehydrated fresh cut kiwis. J. Food Meas. Charact. 2021, 15, 4354-4370, https://doi.org/10.1007/s11694021-01017-2.

54. Lu, S.; Luo, Y.; Turner, E.; Feng, H. Efficacy of sodium chlorite as an inhibitor of enzymatic browning in apple slices. Food Chem. 2007, 104, 824-829, https://doi.org/10.1016/j.foodchem.2006.12.050.

55. Adiletta, G.; Zampella, L.; Coletta, C.; Petriccione, M. Chitosan Coating to Preserve the Qualitative Traits and Improve Antioxidant System in Fresh Figs (Ficus carica L.). Agric. 2019, 9, 84, https://doi.org/10.3390/agriculture9040084.

56. Zheng, H.; Liu, W.; Liu, S.; Liu, C.; Zheng, L. Effects of melatonin treatment on the enzymatic browning and nutritional quality of fresh-cut pear fruit. Food Chem. 2019, 299, 125116, https://doi.org/10.1016/j.foodchem.2019.125116.

57. Saito, S.; Kawabata, J. Synergistic Effects of Thiols and Amines on Antiradical Efficiency of Protocatechuic Acid. J. Agric. Food Chem. 2004, 52, 8163-8168, https://doi.org/10.1021/jf048970j.

58. Zhang, Z.; Huber, D.J.; Qu, H.; Yun, Z.; Wang, H.; Huang, Z.; Huang, H.; Jiang, Y. Enzymatic browning and antioxidant activities in harvested litchi fruit as influenced by apple polyphenols. Food Chem. 2015, 171, 191-199, https://doi.org/10.1016/j.foodchem.2014.09.001.

59. Ali, S.; Anjum, M.A.; Nawaz, A.; Naz, S.; Hussain, S.; Ejaz, S.; Sardar, H. Effect of pre-storage ascorbic acid andAloe veragel coating application on enzymatic browning and quality of lotus root slices. J. Food Biochem. 2020, 44, e13136, https://doi.org/10.1111/jfbc.13136.

60. Schwanninger, M.; Rodrigues, J.; Pereira, H.; Hinterstoisser, B. Effects of short-time vibratory ball milling on the shape of FT-IR spectra of wood and cellulose. Vib. Spectrosc. 2004, 36, 23-40, https://doi.org/10.1016/j.vibspec.2004.02.003.

61. Oh, S.Y.; Yoo, D., II; Shin, Y.; Seo, G. FTIR analysis of cellulose treated with sodium hydroxide and carbon dioxide. Carbohydr. Res. 2005, 340, 417-428, https://doi.org/10.1016/j.carres.2004.11.027. 
62. Movasaghi, Z.; Rehman, S.; Rehman, I.U. Fourier Transform Infrared (FTIR) Spectroscopy of Biological Tissues. Appl. Spectrosc. Rev. 2008, 43, 134-179, https://doi.org/10.1080/05704920701829043.

63. Anjos, O.; Campos, M.G.; Ruiz, P.C.; Antunes, P. Application of FTIR-ATR spectroscopy to the quantification of sugar in honey. Food Chem. 2015, 169, 218-223, https://doi.org/10.1016/j.foodchem.2014.07.138.

64. Ying, D.; Hlaing, M.; Lerisson, J.; Pitts, K.; Cheng, L.; Sanguansri, L.; Augustin, M.A. Physical properties and FTIR analysis of rice-oat flour and maize-oat flour based extruded food products containing olive pomace. Food Res. Int. 2017, 100, 665-673, https://doi.org/10.1016/j.foodres.2017.07.062.

65. Bouyanfif, A.; Liyanage, S.; Hequet, E.; Moustaid-Moussa, N.; Abidi, N. FTIR microspectroscopy reveals fatty acid-induced biochemical changes in C. elegans. Vib. Spectrosc. 2019, 102, 8-15, https://doi.org/10.1016/j.vibspec.2019.03.002.

66. Hssaini, L.; Razouk, R.; Charafi, J.; Houmanat, K.; Hanine, H. Fig seeds: Combined approach of lipochemical assessment using gas chromatography and FTIR-ATR spectroscopy using chemometrics. Vib. Spectrosc. 2021, 114, 103251, https://doi.org/10.1016/j.vibspec.2021.103251.

67. Rabelo, S.; Ferraz, V.P.; Oliveira, L.S.; Franca, A.S. FTIR Analysis for Quantification of Fatty Acid Methyl Esters in Biodiesel Produced by Microwave-Assisted Transesterification. Int. J. Environ. Sci. Dev. 2015, 6, 964-969, doi:10.7763/ijesd.2015.v6.730.

68. Hssaini, L.; Elfazazi, K.; Razouk, R.; Ouaabou, R.; Hernandez, F.; Hanine, H.; Charafi, J.; Houmanat, K.; Aboutayeb, R. Combined Effect of Cultivar and Peel Chromaticity on Figs' Primary and Secondary Metabolites: Preliminary Study Using Biochemical and FTIR Fingerprinting Coupled to Chemometrics. Biol. 2021, 10, 573, https://doi.org/10.3390/biology10070573.

69. Gok, S.; Severcan, M.; Goormaghtigh, E.; Kandemir, I.; Severcan, F. Differentiation of Anatolian honey samples from different botanical origins by ATR-FTIR spectroscopy using multivariate analysis. Food Chem. 2015, 170, 234-240, https://doi.org/10.1016/j.foodchem.2014.08.040.

70. Vongsvivut, J.; Heraud, P.; Gupta, A.; Puri, M.; McNaughton, D.; Barrow, C.J. FTIR microspectroscopy for rapid screening and monitoring of polyunsaturated fatty acid production in commercially valuable marine yeasts and protists. Anal. 2013, 138, 6016-6031, https://doi.org/10.1039/C3AN00485F.

71. Agrebi, F.; Ghorbel, N.; Bresson, S.; Abbas, O.; Kallel, A. Study of nanocomposites based on cellulose nanoparticles and natural rubber latex by ATR/FTIR spectroscopy: The impact of reinforcement. Polym. Compos. 2019, 40, 2076-2087, https://doi.org/10.1002/pc.24989.

72. Jacob, S.P.; Prasad, V.; Sivasankar, S.; Muralidharan, P. Biosynthesis of silver nanoparticles using dried fruit extract of Ficus carica - Screening for its anticancer activity and toxicity in animal models. Food Chem. Toxicol. 2017, 109, 951-956, https://doi.org/10.1016/j.fct.2017.03.066.

73. Coimbra, M.A.; Barros, A.; Rutledge, D.N.; Delgadillo, I. FTIR spectroscopy as a tool for the analysis of olive pulp cell-wall polysaccharide extracts. Carbohydr. Res. 1999, 317, 145-154, https://doi.org/10.1016/S0008-6215(99)00071-3.

74. Vardin, H.; Tay, A.; Ozen, B.; Mauer, L. Authentication of pomegranate juice concentrate using FTIR spectroscopy and chemometrics. Food Chem. 2008, 108, 742-748, https://doi.org/10.1016/j.foodchem.2007.11.027.

75. Baltacıoğlu, H.; Bayındırlı, A.; Severcan, M.; Severcan, F. Effect of thermal treatment on secondary structure and conformational change of mushroom polyphenol oxidase (PPO) as food quality related enzyme: A FTIR study. Food Chem. 2015, 187, 263-269, https://doi.org/10.1016/j.foodchem.2015.04.097. 